\title{
Electrochemical Recovery and Behaviors of Rare Earth (La, Ce, Pr, Nd, Sm, Eu, Gd, Tb, Dy, Ho, Er, Tm, and Yb) Ions on Ni Sheets
}

\author{
Min Hee Joo ${ }^{1,2}$, So Jeong Park ${ }^{1}$, Sung Min Hong ${ }^{1,2}$, Choong Kyun Rhee ${ }^{1}$ \\ and Youngku Sohn 1,2,*(D) \\ 1 Department of Chemistry, Chungnam National University, Daejeon 34134, Korea; \\ wnalsgm14803@naver.com (M.H.J.); jsjs5921@naver.com (S.J.P.); qwqe212@naver.com (S.M.H.); \\ ckrhee@cnu.ac.kr (C.K.R.) \\ 2 Department of Chemical Engineering and Applied Chemistry, Chungnam National University, \\ Daejeon 34134, Korea \\ * Correspondence: youngkusohn@cnu.ac.kr; Tel.: +82-42-821-6548
}

Received: 30 October 2020; Accepted: 20 November 2020; Published: 24 November 2020

\begin{abstract}
The electrochemical behaviors of rare earth (RE) ions have extensively been studied because of their high potential applications to the reprocessing of used nuclear fuels and RE-containing materials. In the present study, we fully investigated the electrochemical behaviors of RE(III) (La, Ce, $\mathrm{Pr}, \mathrm{Nd}, \mathrm{Sm}, \mathrm{Eu}, \mathrm{Gd}, \mathrm{Tb}, \mathrm{Dy}, \mathrm{Ho}, \mathrm{Er}, \mathrm{Tm}$, and $\mathrm{Yb}$ ) ions over a $\mathrm{Ni}$ sheet electrode in $0.1 \mathrm{M} \mathrm{NaClO}_{4}$ electrolyte solution by cyclic voltammetry between +0.5 and $-1.5 \mathrm{~V}$ (vs. Ag/AgCl). Amperometry electrodeposition experiments were performed between -1.2 and $-0.9 \mathrm{~V}$ to recover RE elements over the Ni sheet. The successfully RE-recovered $\mathrm{Ni}$ sheets were fully characterized by scanning electron microscopy, energy dispersive X-ray spectroscopy, Fourier transform infrared spectroscopy, X-ray photoelectron spectroscopy, and photoluminescence spectroscopy. The newly reported recovery data for RE(III) ions over a metal electrode provide valuable information on the development of the treatment methods of RE elements.
\end{abstract}

Keywords: rare earth ions; electrochemical recovery; amperometry electrodeposition; cyclic voltammetry; actinide ions

\section{Introduction}

Rare earth (RE) elements have widely been used in diverse industry materials such as magnets, fluorescent lamps, catalysts, and batteries [1-5]. Lanthanide (Ln) elements are commonly co-present with actinide (An) elements in nuclear oxide fuels. Therefore, the treatment and the recycling of used RE-containing industry materials and oxide fuels are of very attractive research projects [6-10]. In the reprocessing of spent nuclear oxide fuels, the pyroprocessing technology has been employed to reprocess Ln and An ions present in a pre-prepared electrolyte condition [11]. For this treatment, electrochemistry is an indispensable technique, and the understanding electrochemical behaviors (e.g., electrochemical reduction-oxidation reactions) of the ions over electrodes is very important. For the recovery of RE elements from used industry materials [12,13], the electrochemical recovery method has been a useful method to selectively recover a desired element in an electrolyte with mixed RE ions [12-14]. To achieve these goals, electrochemical behaviors of RE ions in an electrolyte have fundamentally been studied by electrochemistry [15-19]. Yang et al. studied electrochemical behaviors and electrodeposition of $\mathrm{Eu}$ (III) ions over a Al-Ga cathode, and co-reduction behaviors of $\mathrm{Eu}(\mathrm{III}), \mathrm{Al}(\mathrm{III})$ and $\mathrm{Ga}(\mathrm{III})$ over a W electrode [16]. They showed efficient reduction and co-reduction of $\mathrm{Eu}(\mathrm{III})$ ions over the electrodes. Liu et al. studied direct separation of $\mathrm{U}$ from $\mathrm{RE}(\mathrm{La}, \mathrm{Nd}, \mathrm{Ce}$, 
and $\mathrm{Sm}$ )-containing $\mathrm{LiCl}-\mathrm{KCl}$ eutectic and showed that $\mathrm{U}$ was efficiently electrodeposited as $\mathrm{Al}-\mathrm{U}$ alloys $\left(\mathrm{Al}_{3} \mathrm{U}\right.$ and $\left.\mathrm{Al}_{4} \mathrm{U}\right)$ on the $\mathrm{Al}$ electrode [17]. Kim and Lee focused on obtaining fundamental electrochemical properties of both $\mathrm{Nd}^{3+/} \mathrm{Nd}^{2+}$ and $\mathrm{Ce}^{3+} / \mathrm{Ce}$ in a molten $\mathrm{LiCl}-\mathrm{KCl}$ eutectic salt at a high temperature of $773 \mathrm{~K}$ using a glassy carbon counter electrode, a $\mathrm{Ag} / \mathrm{Ag}^{+}$reference electrode, and a W working electrode, and reported the measured diffusion constant, the standard reduction potential, and the standard-state Gibb's free energy of the RE ions [18]. Separation of a neighboring RE pair (e.g., $\mathrm{Sm}^{3+} \mathrm{Sm}^{2+}$ and $\mathrm{Eu}^{3+/} \mathrm{Eu}^{2+}$ ) is another goal to be achieved. Ge et al. used a reactive $\mathrm{Cu}$ electrode for selective recovery as $\mathrm{Cu}-\mathrm{Sm}$ intermetallic compounds [19]. Al-Eu compound was reported to be selectively recovered over an $\mathrm{Al}$ electrode at a negative potential of $-2.225 \mathrm{~V}\left(\mathrm{vs}\right.$. $\mathrm{Ag} / \mathrm{Ag}^{+}$), higher than that of Al-Sm compound recovery on the electrode [19]. The molten-salt condition has commonly been performed at a high temperature [16-19] while the electrodeposition in ionic liquid conditions has been introduced for a mild temperature condition [20-22]. Xu et al. efficiently electrodeposited a rare earth iron alloy of Nd-Fe film on a Cu electrode in an ionic liquid condition containing $\mathrm{Nd}(\mathrm{III})$ and $\mathrm{Fe}(\mathrm{II})$ ions [20]. They proposed a deposition mechanism that Fe was initially deposited to subsequently catalyze the reduction of $\mathrm{Nd}(\mathrm{III})$ to $\mathrm{Nd}(0)$, and consequently $\mathrm{Nd}-\mathrm{Fe}$ was co-deposited.

Although there are many literatures for the recovery of RE elements under various conditions, few studies have been systematically reported for the recovery of all the RE elements over a metal electrode in a $\mathrm{NaClO}_{4}$ condition at room temperature. Because the electrochemical behaviors of RE and An elements are very similar, the selective recovery and the treatment are challenging and needed to be continuously developed. The novelty of this study is that all the RE elements were introduced to show that they had a systematic relationship on redox potentials with atomic number. Therefore, this data set is very useful for better understanding the redox behaviors of rare earth ions and the development of Ln and An treatment methods as well as other heavy metal ions present in water.

\section{Results and Discussion}

To examine the electrochemical behaviors of RE(III) ions, Figure 1 displays cyclic voltammetry (CV) curves for various $10 \mathrm{mM} \mathrm{RE}(\mathrm{III})$ ions in $0.1 \mathrm{M} \mathrm{NaClO}_{4}$ electrolyte over bare Ni sheets. In a blank $0.1 \mathrm{M} \mathrm{NaClO}_{4}$ electrolyte, there was no discernible reduction-oxidation (redox) peaks except for the current increases below $-1.0 \mathrm{~V}$ (vs. $\mathrm{Ag} / \mathrm{AgCl}$ ) and above $0.0 \mathrm{~V}$. Upon addition of $10 \mathrm{mM} \mathrm{RE}$ (III) ions, a strong negative current increase was commonly observed, starting from $-0.5 \mathrm{~V}$. There was no significant current increase between -0.5 and $+0.5 \mathrm{~V}$. The negative current increase was due to both the hydrogen evolution reaction and the RE reduction/complexation. Interestingly, as the atomic number was increased (or as the atomic size was decreased) from \#57 (La) to \#70 $(\mathrm{Yb})$, the reduction peak became distinctly appeared. This indicates that the reduction potentials for $\mathrm{La}(\# 57), \mathrm{Ce}(\# 58)$, and $\operatorname{Pr}(\# 59)$ are close to the hydrogen reduction potential, and the reduction potentials for $\operatorname{Er}(\# 68)$, Tm (\#69), and $\mathrm{Yb}$ (\#70) are far from the hydrogen reduction potential. The reduction potential for La was barely detected at $-1.2 \mathrm{~V}$ (vs. $\mathrm{Ag} / \mathrm{AgCl}$ ) and that for $\mathrm{Yb}$ was clearly seen at $-0.95 \mathrm{~V}$ (vs. $\mathrm{Ag} / \mathrm{AgCl}$ ). The reduction potentials for $\mathrm{Nd}, \mathrm{Sm}$, and Eu were observed to be between -1.11 and $-0.92 \mathrm{~V}$ (vs. $\mathrm{Ag} / \mathrm{AgCl}$ ). $\mathrm{Xu}$ et al. reported that the equilibrium potentials of RE elements were in a relationship with atomic size [23]. Herein, the present redox potentials of RE(III) ions appear to be also influenced by other factors such as electronegativity and complex formation degree.

To examine the electrochemical recovery of RE(III) ions over Ni sheets and the corresponding morphology, Figure 2 shows scanning electron microscope (SEM) and optical microscope images before and after electrodeposition. On the basis of the images, all the RE elements were efficiently deposited on $\mathrm{Ni}$ sheets. The deposited areas were clearly discriminated from the undeposited areas by optical microscope images. For the SEM images of $\mathrm{La}, \mathrm{Ce}$, and $\mathrm{Pr}$, the surface morphology showed a uniform film state, although some cracks were present in the deposited areas. For the SEM images of Nd, Sm, $\mathrm{Eu}, \mathrm{Gd}$, and $\mathrm{Tb}$, the morphology appeared to be a film state aggregated by ultrafine particles. For the SEM images of Dy, Ho, Er, Tm, and $\mathrm{Yb}$, the particle sizes were appeared to be much bigger and become nanoparticle structures. Overall, it can be concluded that the morphology was changed from uniform 
thin film state to nanoparticle structures as the atomic number was increased. The present data can provide valuable information on the development of thin film fabrication by electrodeposition.
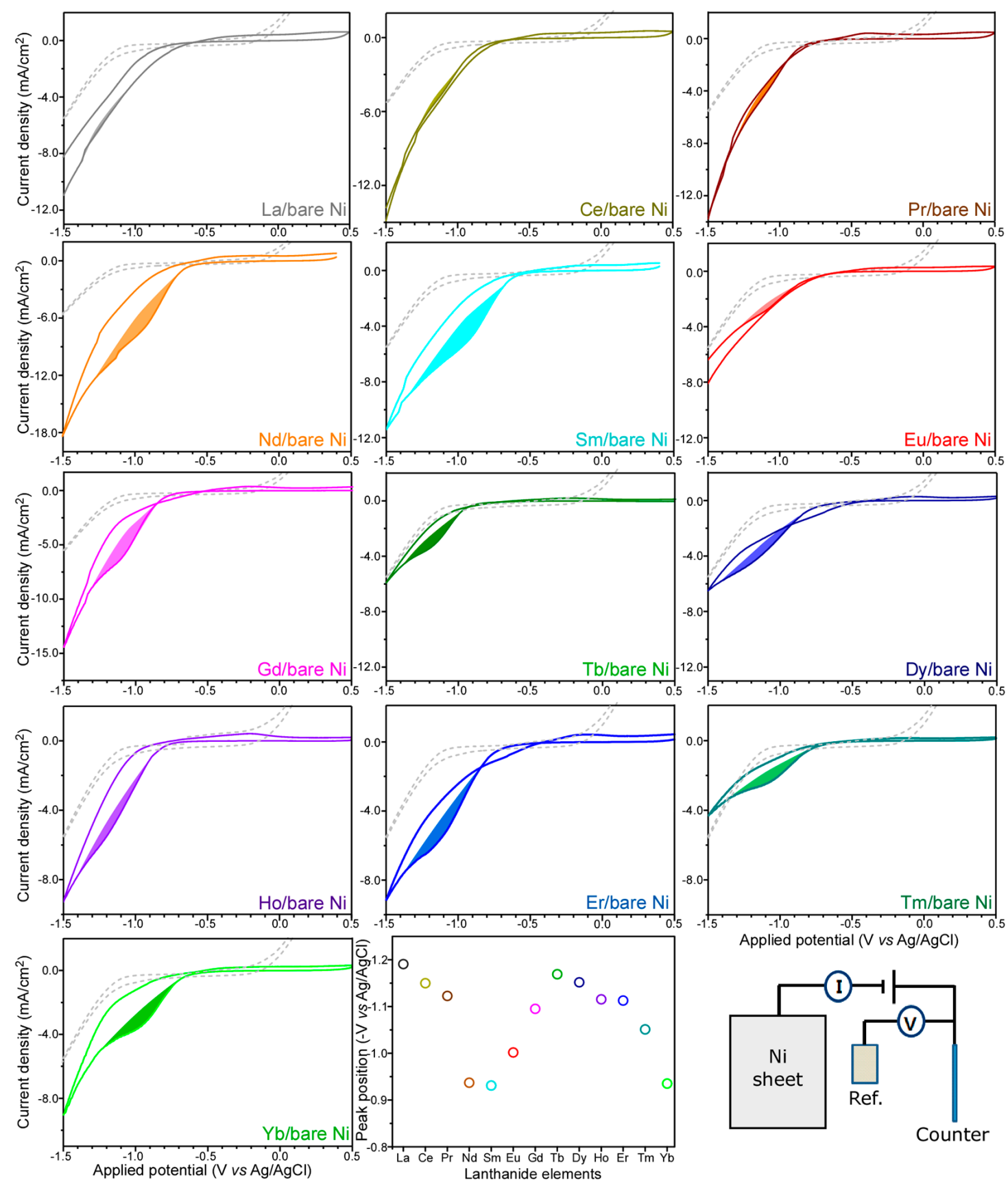

Figure 1. Cyclic voltammetry curves at a scan rate of $0.2 \mathrm{~V} / \mathrm{s}$ for various $10 \mathrm{mM}$ RE(III) ions in $0.1 \mathrm{M}$ $\mathrm{NaClO}_{4}$ electrolyte over bare Ni sheets. The reduction peak positions ( $\mathrm{V}$ vs. $\mathrm{Ag} / \mathrm{AgCl}$ ) are shown with RE elements. A schematic of the three-electrode system used in this study is shown.

To confirm the elements of the recovered RE elements, Figure 3 shows the energy-dispersive X-ray spectroscopy (EDXS) data for the samples shown in Figure 2. For the EDX spectrum (not shown here) of a bare Ni sheet, the detected signals were of $\mathrm{Ni}$ (major), $\mathrm{C}$ (minor), and $\mathrm{O}$ (minor) elements: $\mathrm{Ni} \mathrm{L}$ $(0.84 \mathrm{KeV}), \mathrm{C} \mathrm{K}(0.26 \mathrm{KeV})$, and $\mathrm{O} \mathrm{K}(0.52 \mathrm{KeV})$ [24]. Upon electrodeposition, the signals of RE, C, and O were strongly increased. The strong $\mathrm{O}$ signal was plausibly due to $\mathrm{RE}-\mathrm{O},-\mathrm{OH},-\mathrm{ClO}_{4}$, and $-\mathrm{CO}_{3}$ species, confirmed by Fourier transform infrared spectroscopy (FT-IR) and X-ray photoelectron spectroscopy (XPS) shown below. The EDXS signals of $\mathrm{RE}$ and $\mathrm{Cl}(\mathrm{Cl} \mathrm{K}=2.62 \mathrm{KeV})$ elements were newly appeared. 
The $\mathrm{Cl} \mathrm{K}$ signal was due to $\mathrm{ClO}_{4}$ species, further discussed in the FT-IR spectra below. The Ni L signals were observed to be dependent on the amounts of RE deposited on a Ni sheet. The Gd/Ni sample showed the strongest Ni signal while Dy/Ni showed the weakest signal. This indicates that Dy element was the most recovered by electrodeposition after a given time for $5 \mathrm{~min}$. For the EDXS signals (Ln M) of RE elements, the peak position was linearly increased to a higher energy position with increasing the atomic number. The La M (\#57 for La element) and the Yb M (\#70 for Yb element) signals were positioned at 0.83 and $1.52 \mathrm{KeV}$, respectively [24]. The peak separation between the two peaks was estimated to be $0.69 \mathrm{KeV}$. For the radioactive promethium, Pm M can be expected to be observed around $1.1 \mathrm{KeV}$. On the basis of inductively coupled plasma elemental analysis of Ce and the Ln M EDXS signal intensities, the recovery percentages (\%) were roughly estimated to be La (15.6\%), Ce (3\%), $\operatorname{Pr}(3.2 \%)$, Nd (5.7\%), Sm (5.9\%), Eu (4.3\%), Gd (2.7\%), Tb (3.3\%), Dy (12.6\%), Ho (11.5\%), Er (12.7\%), $\operatorname{Tm}(15.3 \%)$, and $\mathrm{Yb}(18.7 \%)$ over a $5 \mathrm{~mm} \times 10 \mathrm{~mm}$ size electrode in $5 \mathrm{~min}$.

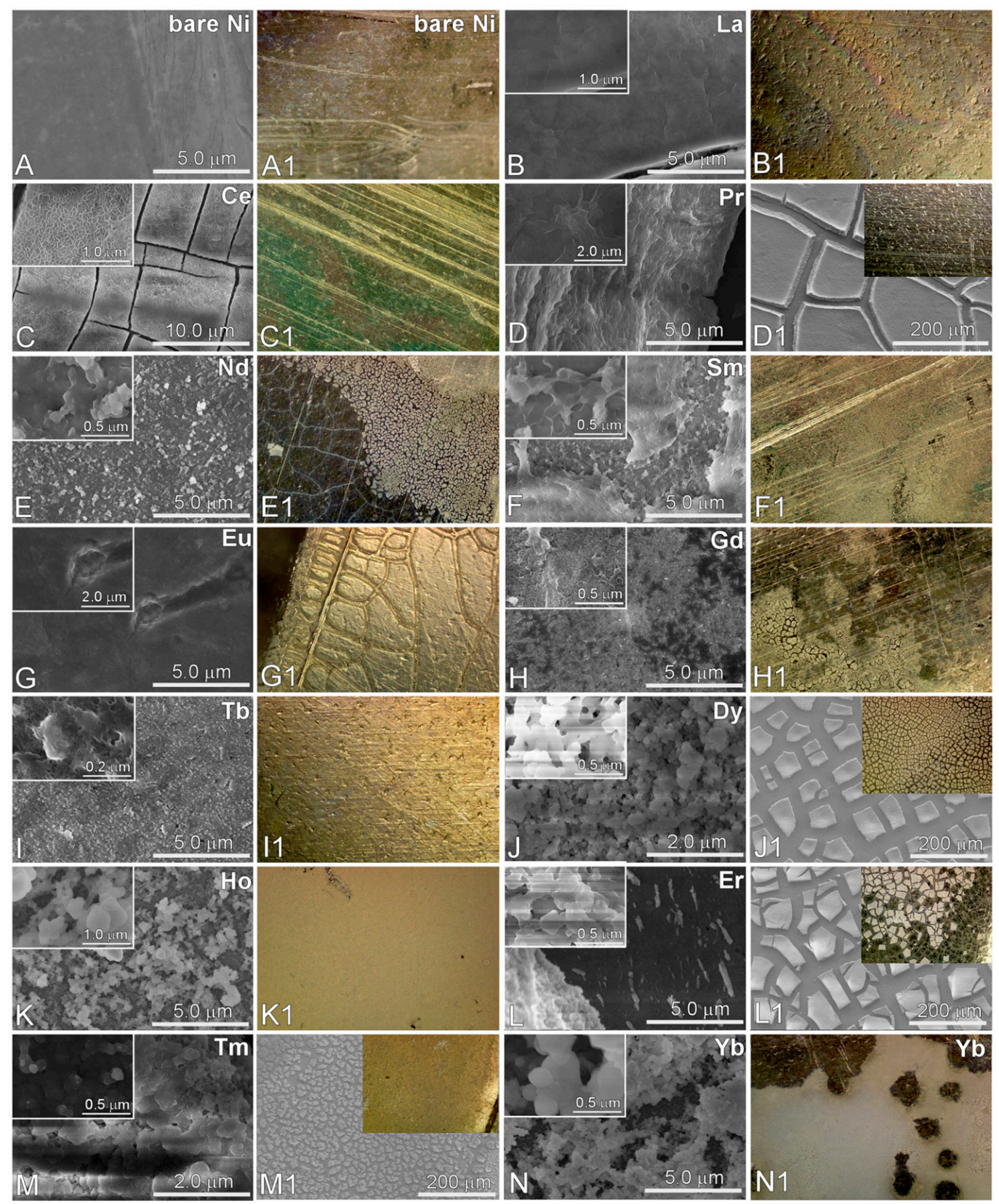

Figure 2. SEM images (A-N) and optical microscope (300×) images (A1-N1) are shown for a bare Ni sheet (A) and electrodeposited RE elements on a Ni sheet (from $\mathbf{B}-\mathbf{N}$ ). 


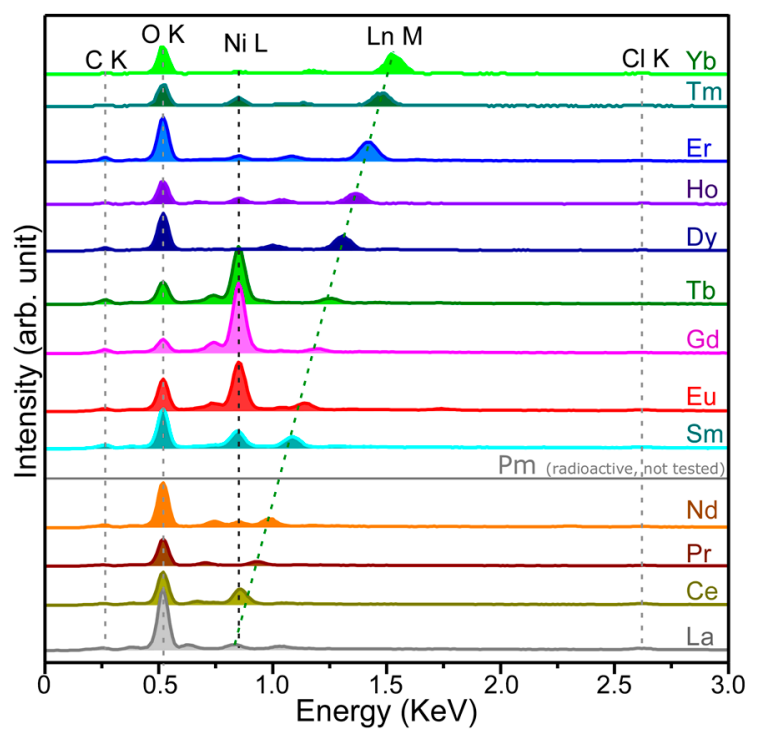

Figure 3. Energy-dispersive X-ray spectroscopy (EDXS) data for electrodeposited RE elements over a Ni sheet.

To deduce the chemical structures of the electrodeposited materials, Figure 4 displays the FT-IR spectra for all the electrodeposited samples. Very interestingly, all the FT-IR spectra were found to be similar, except for the signal intensity, which was determined by the amounts of recovered materials. The FT-IR intensity was in good consistent with the EDXS signal intensity. The Gd/Ni sample showed the weakest IR intensity. As discussed above, this sample showed the strongest EDXS Ni signal (from the Ni support). This indicates that the electrodeposited Gd was the thinnest. In the FT-IR spectra, a broad peak around $3600 \mathrm{~cm}^{-1}$ was distinctly observed, attributed to RE-OH stretching vibrations [25-28]. The corresponding $\mathrm{O}-\mathrm{H}$ bending vibrational mode was observed at $1625 \mathrm{~cm}^{-1}$. The commonly appeared peak at $620 \mathrm{~cm}^{-1}$ was attributed to a RE-O vibrational mode [26]. A broad peak at $1080 \mathrm{~cm}^{-1}$ could be related with a vibration of $\mathrm{ClO}_{4}{ }^{-}$group [29]. Two strong peaks were also observed at 1350 and $1403 \mathrm{~cm}^{-1}$, the most plausibly attributed to the stretching vibration modes of $\mathrm{CO}_{3}{ }^{2-}$ group [25-28]. On the basis of the FT-IR data, it could be concluded that the electrodeposited samples were complexes of $\mathrm{RE}, \mathrm{OH}\left(\right.$ and/or $\left.\mathrm{H}_{2} \mathrm{O}\right), \mathrm{CO}_{3}{ }^{2-}$, and $\mathrm{ClO}_{4}{ }^{-}$groups, further discussed below.

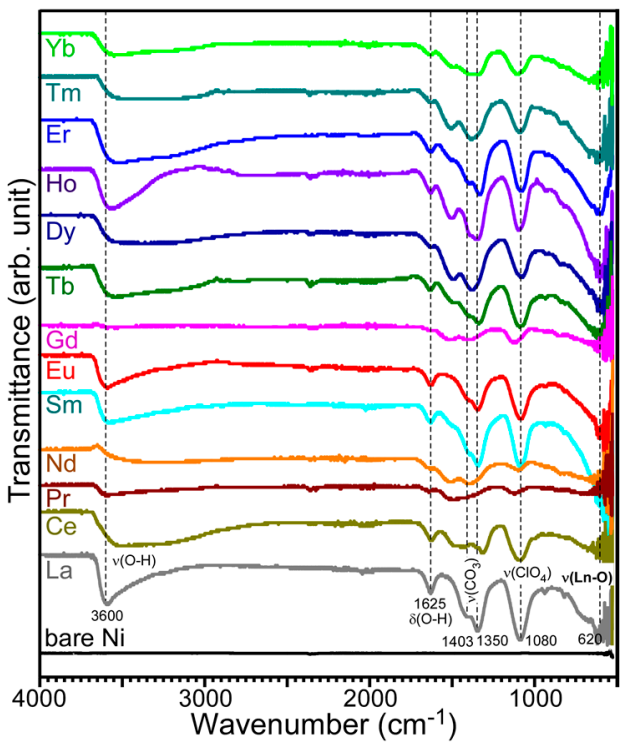

Figure 4. Transmittance FT-IR spectra for electrodeposited RE elements over a Ni sheet. 
To further examine the crystal structures of the electrodeposited samples, the X-ray diffraction (XRD) patterns of a selected Eu sample and a bare Ni were displayed in Figure 5. The XRD signals were barely detected because the film was ultrathin (and low crystallinity), and the electrode was too small to be properly aligned. This needs further investigation to increase a potential applicability. For bare Ni sheet, the XRD signals were very strong and there were no significant impurity signals. The strong peaks at $2 \theta=45^{\circ}$ and $52^{\circ}$ were attributed to the (111) and (200) crystal planes of metallic Ni [30]. The other (but clearly discriminated from the background signal) weak XRD signals were observed around $2 \theta=10^{\circ}, 20^{\circ}, 28^{\circ}$, and $50^{\circ}$. These XRD peak positions are similar to those of $\mathrm{Ln}_{2}(\mathrm{OH})_{x}\left(\mathrm{NO}_{3}\right)_{y}\left(\mathrm{SO}_{4}\right)_{z} \cdot \mathrm{nH}_{2} \mathrm{O}$ complex [25] and metal carbonate hydroxide structures $[25,27,28,31,32]$. Assuming that anions of $\mathrm{SO}_{4}{ }^{2-}$ and $\mathrm{NO}_{3}{ }^{-}$are exchanged by $\mathrm{CO}_{3}{ }^{2-}$ and $\mathrm{ClO}_{4}{ }^{-}$but the crystal phase is not changed [25], the corresponding crystal planes are assigned on the four broad peaks in Figure 5 . Based on the present XRD information, the FT-IR data, and the literature information, the recovered RE elements were proposed to be presented as $\mathrm{RE}_{2}(\mathrm{OH})_{x}\left(\mathrm{CO}_{3}\right)_{y-z}\left(\mathrm{ClO}_{4}\right)_{z} \cdot \mathrm{nH}_{2} \mathrm{O}$ complex, where $\mathrm{O}$ and RE were the most abundantly present in the complex [25]. The EDXS data commonly showed RE, C, O, and $\mathrm{Cl}$ elements, and the atomic compositions of $\mathrm{RE}$ and $\mathrm{O}$ were much higher than those of $\mathrm{C}$ and $\mathrm{Cl}$.

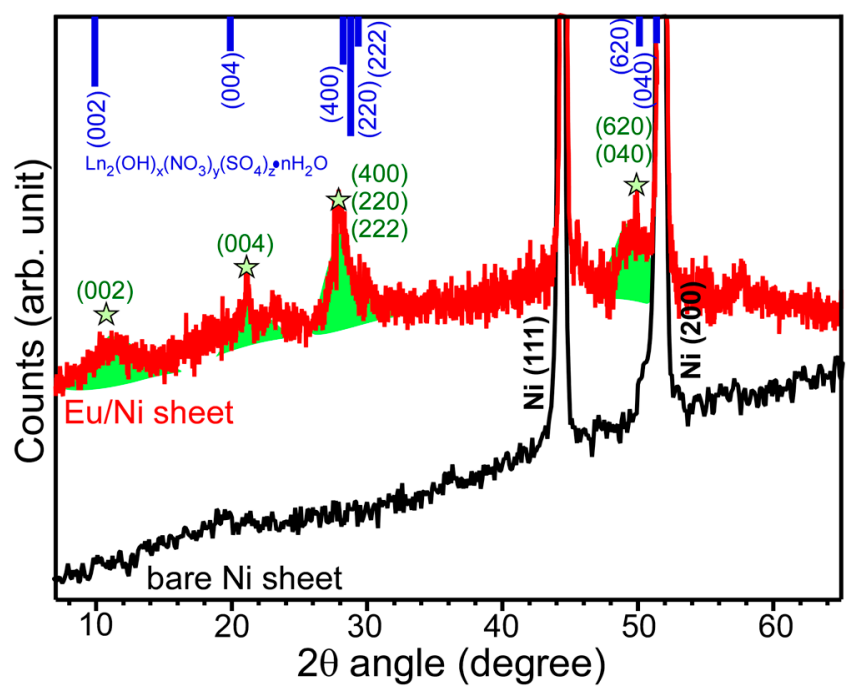

Figure 5. XRD data for bare $\mathrm{Ni}$ and selected electrodeposited $\mathrm{Eu}$ on a Ni sheet. The literature XRD patterns for $\mathrm{Ln}_{2}(\mathrm{OH})_{x}\left(\mathrm{NO}_{3}\right)_{y}\left(\mathrm{SO}_{4}\right)_{z} \cdot \mathrm{nH}_{2} \mathrm{O}$ complex are shown for comparison.

Surface chemical states of a selected electrodeposited sample were examined by X-ray photoelectron spectroscopy (XPS). Figure 6 displays survey, high-resolution C 1s, Ni 2p, and Eu 3d XPS spectra before and after Eu electrodeposition over a Ni sheet. All the binding energies (BEs) here were not calibrated using an internal standard, but the XPS spectrometer showed an Au $4 \mathrm{f}_{7 / 2}$ XPS peak at $84.0 \mathrm{eV}$ for a cleaned $\mathrm{Au}$ film (as an external standard). For the survey XPS scan of a bare Ni sheet, Ni, C and O elements were only observed. An O 1s XPS signal was observed at a BE of $530.2 \mathrm{eV}$ for a bare Ni sheet, due to oxidation of Ni surface. The surface oxide was ultrathin and could not be detected by the bulk XRD technique, shown above. For the survey scan of an electrodeposited Eu on Ni, Eu 3d and $\mathrm{Eu} 4 \mathrm{~d}$ signals were strongly and newly appeared. In addition, $\mathrm{N} 1 \mathrm{~s}$ and $\mathrm{Cl} 2 \mathrm{p}$ XPS signals were also newly appeared. The $\mathrm{N} 1$ s peak position was observed at a $\mathrm{BE}$ of $406.0 \mathrm{eV}[33,34]$, plausibly due to nitrates trapped in the surface. The $\mathrm{Cl} 2 \mathrm{p} \mathrm{BE}$ was observed at $207.0 \mathrm{eV}$, due to $\mathrm{ClO}_{4}$ species $[33,35]$. The $\mathrm{Cl}$ element was also detected by EDXS, shown above. In the $\mathrm{C} 1 \mathrm{~s}$ XPS for bare Ni, two peaks were observed at $283.8 \mathrm{eV}$ (major) and $287.2 \mathrm{eV}$ (minor), attributed to adventitious $\mathrm{C}-\mathrm{C}$ and $\mathrm{C}-\mathrm{O}$ species, respectively. In the C 1s XPS for electrodeposited $\mathrm{Eu}$ on Ni, a C 1 XPS peak at a BE of $288.5 \mathrm{eV}$ was newly observed, attributed to $\mathrm{O}-\mathrm{C}=\mathrm{O}$ species such as carbonates [33]. In the Ni $2 p$ XPS for bare Ni, several peaks were observed. Two shaper peaks at 868.6 and $851.4 \mathrm{eV}$ with a spin orbit splitting of $17.2 \mathrm{eV}$ were assigned to the $\mathrm{Ni} 2 \mathrm{p}_{1 / 2}$ and $\mathrm{Ni} 2 \mathrm{p}_{3 / 2}$ XPS signals of metallic $\mathrm{Ni}[30,33,36]$, respectively. 
Two broader peaks at 872.6 and $854.6 \mathrm{eV}$ with a spin orbit splitting of $17.7 \mathrm{eV}$ were assigned to the $\mathrm{Ni} 2 \mathrm{p}_{1 / 2}$ and $\mathrm{Ni} 2 \mathrm{p}_{3 / 2}$ XPS signals of $\mathrm{Ni}(\mathrm{II})$ state (e.g., $\mathrm{NiO}$ ), respectively [30,36]. The corresponding satellite peaks of $\mathrm{Ni}(\mathrm{II})$ oxidation state were observed at 879.3 and $861.0 \mathrm{eV}$, respectively [33,36]. On the basis of the Ni 2p XPS, the surface of Ni sheet was oxidized to Ni(II) state. Upon Eu deposition, the Ni $2 p$ signal was not observed, an indication that the electrodeposited overlayer was much thicker than the XPS probe depth. In the Eu 3d XPS, two major signals were observed at 1163.3 and $1133.5 \mathrm{eV}$ with a spin-orbit splitting energy of $29.8 \mathrm{eV}$, attributed to $\mathrm{Eu} 3 \mathrm{~d}_{3 / 2}$ and $\mathrm{Eu} 3 \mathrm{~d}_{5 / 2}$ XPS signals of Eu(III) state, respectively [37]. A weaker $\mathrm{Eu} 3 \mathrm{~d}_{3 / 2}$ peak around $1156.0 \mathrm{eV}$ could be due to some $\mathrm{Eu}(\mathrm{II})$ states [37].
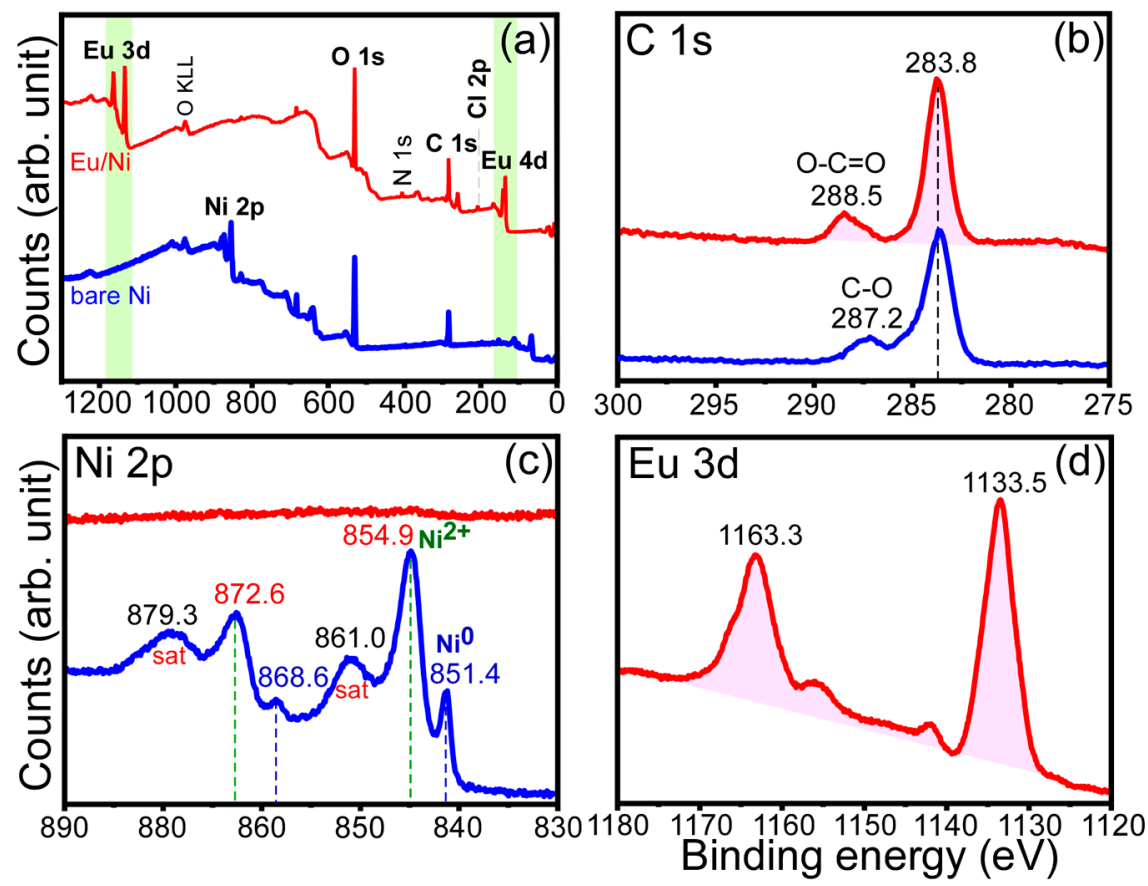

Figure 6. Survey (a), high-resolution C 1s (b), Ni 2p (c), and Eu 3d (d) XPS spectra before and after Eu electrodeposition over a bare Ni sheet.

To further confirm the oxidation state of Eu elements, photoluminescence spectroscopy was employed for the Eu electrodeposited sample because $\mathrm{Eu}(\mathrm{III})$ ion has unique ${ }^{5} \mathrm{D}_{0} \rightarrow{ }^{7} \mathrm{~F}_{0,1,2,3,4}$ transitions in the visible region between 550 and $720 \mathrm{~nm}$ [37-40], while Eu(II) shows no visible light emission under an excitation of UV light. Figure 7 shows excitation and emission spectra for a thick electrodeposited Eu sample and the corresponding 2D- and 3D-PL contour mapping images. For the excitation spectra setting at emission wavelengths $\left(\lambda_{\mathrm{em}}\right)$ of 613 and $590 \mathrm{~nm}$, the PL profiles were found to be very similar, but the intensity was stronger for the spectra at $\lambda_{\mathrm{em}}=613 \mathrm{~nm}$. This indicates that the emission under $613 \mathrm{~nm}$ light was stronger than the emission under $590 \mathrm{~nm}$ light. Various peaks were observed at $299,319,363,383,395,416$, and $466 \mathrm{~nm}$, assigned to the ${ }^{5} \mathrm{~F}_{4},{ }^{5} \mathrm{H}_{5},{ }^{5} \mathrm{D}_{4},{ }^{5} \mathrm{G}_{\mathrm{J}} /{ }^{5} \mathrm{~L}_{7},{ }^{5} \mathrm{~L}_{6},{ }^{5} \mathrm{D}_{3}$, and ${ }^{5} \mathrm{D}_{2}$ transitions from the ground ${ }^{7} \mathrm{~F}_{0}$ state of $\mathrm{Eu}(\mathrm{III})$, respectively [37]. For the emission spectra taken at excitation wavelengths ( $\left.\lambda_{\mathrm{ex}}\right)$ of $280 \mathrm{~nm}$ (indirect excitation), $320 \mathrm{~nm}$ (the ${ }^{5} \mathrm{~F}_{4} \leftarrow{ }^{7} \mathrm{~F}_{0}$ direct excitation), and $395 \mathrm{~nm}$ (the ${ }^{5} \mathrm{~L}_{6} \leftarrow{ }^{7} \mathrm{~F}_{0}$ direct excitation), the two emission profiles at direct excitations of $\lambda_{\mathrm{ex}}=320$ and $395 \mathrm{~nm}$ are similar, but the emission profile at an indirect excitation of $\lambda_{\mathrm{ex}}=280 \mathrm{~nm}$ is dissimilar to the other two. The PL intensity of the direct transition to an Eu(III) excited energy level was found to be stronger than that of the indirect transition. Several PL peak positions were commonly observed at 578 , $590,613,647$, and $698 \mathrm{~nm}$, commonly associated to the ${ }^{5} \mathrm{D}_{0} \rightarrow{ }^{7} \mathrm{~F}_{0},{ }^{5} \mathrm{D}_{0} \rightarrow{ }^{7} \mathrm{~F}_{1},{ }^{5} \mathrm{D}_{0} \rightarrow{ }^{7} \mathrm{~F}_{2},{ }^{5} \mathrm{D}_{0} \rightarrow{ }^{7} \mathrm{~F}_{3}$, and ${ }^{5} \mathrm{D}_{0} \rightarrow{ }^{7} \mathrm{~F}_{4}$, transitions, respectively [37-40]. The ${ }^{5} \mathrm{D}_{0} \rightarrow{ }^{7} \mathrm{~F}_{2}$ transition was observed to be the most intense. Because of the strong emission, the sample appeared to be red for the electrodeposited $\mathrm{Eu}$ (inset photo in Figure 7A). The ${ }^{5} \mathrm{D}_{0} \rightarrow{ }^{7} \mathrm{~F}_{2}$ transition is known to be electric dipole transition and hypersensitive to Eu(III) local environment. The transition becomes dominant when Eu(III) ion is 
located at an asymmetric site. On the other hand, the ${ }^{5} \mathrm{D}_{0} \rightarrow{ }^{7} \mathrm{~F}_{1}$ transition is insensitive to the local environment. For this reason, $\left({ }^{5} \mathrm{D}_{0} \rightarrow{ }^{7} \mathrm{~F}_{2}\right) /\left({ }^{5} \mathrm{D}_{0} \rightarrow{ }^{7} \mathrm{~F}_{1}\right)$ intensity ratio is regarded as an asymmetric ratio for $\mathrm{Eu}(\mathrm{III})$ location site. The ratio was estimated to be 2.3 for the emission spectra at direction excitations. The ratio was 1.2 for the emission at indirect excitation. The corresponding 2D and 3D contour PL mapping profiles show densely spaced regions, an indication of strong emission signals. The densely spaced regions are mainly localized at the upper energy levels $\left({ }^{5} \mathrm{~F}_{4},{ }^{5} \mathrm{H}_{5},{ }^{5} \mathrm{D}_{4},{ }^{5} \mathrm{G}_{\mathrm{J}} /{ }^{5} \mathrm{~L}_{7},{ }^{5} \mathrm{~L}_{6}\right.$, ${ }^{5} \mathrm{D}_{3}$, and $\left.{ }^{5} \mathrm{D}_{2}\right) \leftarrow{ }^{7} \mathrm{~F}_{0}$ excitation transitions and ${ }^{5} \mathrm{D}_{0} \rightarrow{ }^{7} \mathrm{~F}_{0,1,2,3,4}$ emission transitions.
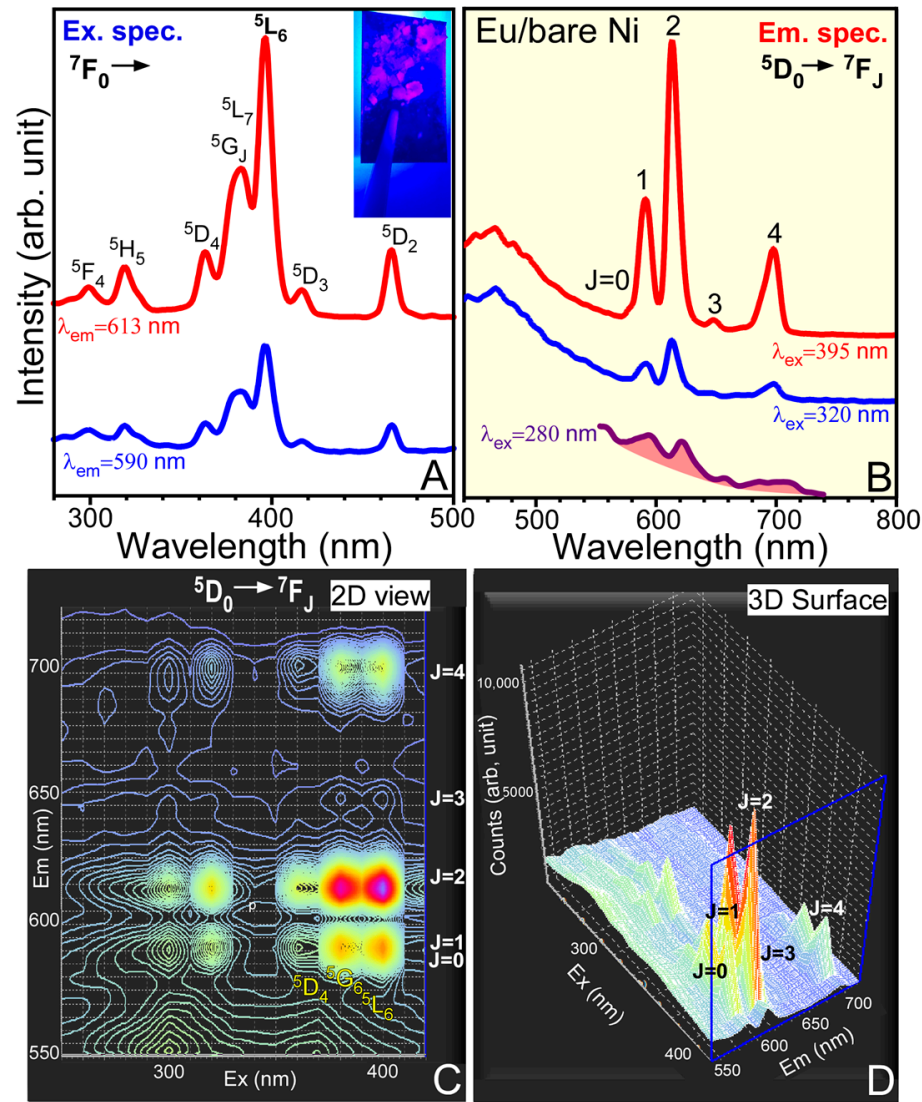

Figure 7. Excitation (A) and emission (B) spectra for a thick electrodeposited Eu on a Ni sheet, and the corresponding 2D- and 3D-PL contour mapping images (C, D).

\section{Experimental Section}

\subsection{Sample Preparations}

Ni sheets $(99.96 \%)$ were cut with a size of $5 \mathrm{~mm} \times 20 \mathrm{~mm}$; cleaned by ultrasonication in acetone, isopropyl alcohol, and water, repeatedly; and dried under an infrared lamp. All the purchased RE(III) ions were nitrate forms and used as received without any further purification: La(III) nitrate hexahydrate (99.999\%, Sigma-Aldrich, Saint Louis, MO, USA), Ce(III) nitrate hexahydrate (99\%, Sigma-Aldrich), $\operatorname{Pr}(\mathrm{III})$ nitrate pentahydrate (99.9\%, Alfa Aesar, Ward Hill, MA, USA), Nd(III) nitrate hexahydrate (99.9\%, Alfa Aesar), Sm(III) nitrate hexahydrate (99.9\%, Alfa Aesar), Eu(III) nitrate hexahydrate (99.9\%, Alfa Aesar), Gd(III) nitrate hexahydrate (99.9\%, Sigma-Aldrich), Tb(III) nitrate hydrate (99.9\%, Alfa Aesar), Dy(III) nitrate pentahydrate (99.9\%, Sigma-Aldrich), Ho(III) nitrate pentahydrate (99.99\%, Alfa Aesar), Er(III) nitrate hydrate (99.9\%, Sigma-Aldrich), Tm(III) nitrate hydrate (99.9\%, Alfa Aesar), and $\mathrm{Yb}(\mathrm{III})$ nitrate hydrate (99.9\%, Sigma Aldrich). Sodium perchlorate $\left(\mathrm{NaClO}_{4} \geq 98.0 \%\right.$, Sigma-Aldrich) was used as received and made to an aqueous $0.1 \mathrm{M}$ solution as a supporting electrolyte. RE(III) ions were $10 \mathrm{mM}$ concentration in the supporting electrolyte. Cyclic voltammetry tests were conducted using a WPG100 Potentiostat/Galvanostat (WonATech Co., Ltd., Seoul, Korea) 
electrochemical workstation. with a conventional three-electrode arrangement: a $\mathrm{Ag} / \mathrm{AgCl}(3.5 \mathrm{M} \mathrm{KCl})$ reference electrode, a Pt wire $(0.5 \mathrm{~mm})$ counter electrode, and a Ni sheet electrode $(5 \mathrm{~mm} \times 20 \mathrm{~mm})$ in a $0.1 \mathrm{M} \mathrm{NaClO}_{4}$ electrolyte with and without $\mathrm{RE}(\mathrm{III})$ ions $(10 \mathrm{mM})$. For the recovery of the RE elements, the electrodeposition over a Ni sheet was performed by amperometry for 5 min setting at the reduction potential observed in the CV data. After the electrodeposition, the electrode was gently washed with deionized water and dried under an infrared lamp before further characterization.

\subsection{Characterization of the RE Recovered Materials}

The morphology of the RE-recovered samples was examined using a field-emission Hitachi S-4800 SEM (FE-SEM, Hitach Ltd., Tokyo, Japan). The crystal phases of the electrodeposited sample were identified using a MiniFlex II X-ray diffractometer (Rigaku Corp., Tokyo, Japan) equipped with a $\mathrm{Cu} \mathrm{K} \alpha$ radiation source. Energy-dispersive X-ray spectroscopy (EDXS) was performed using a JSM $7000 \mathrm{~F}$ scanning electron microscope (JEOL Ltd., Tokyo, Japan) at an acceleration voltage of $20 \mathrm{kV}$. The FT-IR spectra were recorded using a Nicolet iS 10 FT-IR spectrometer (Thermo Scientific Korea, Seoul, Korea) with an attenuated total reflection mode. Photoluminescence (PL) emission and excitation spectra were obtained using a Sinco FS-2 fluorescence spectrometer (Sinco, Seoul, Korea) setting at scan speed $=300 \mathrm{~nm} / \mathrm{min}$, slit width $=5 \mathrm{~nm}$, PMT voltage $=700 \mathrm{~V}$, and integration time $=20 \mathrm{~ms}$. The emission profiles were recorded at various excitation wavelengths to plot 2D/3D PL contour profiles. X-ray photoelectron spectroscopy was employed using Thermo-VG Scientific K-alpha ${ }^{+}$spectrometer (Thermo VG Scientific, Waltham, MA, USA) with a monochromatic Al $K_{\alpha} X$-ray source (spot size $=400 \mu \mathrm{m}$ ) and a hemispherical energy analyzer (CAE mode, pass energy $=50.0 \mathrm{eV}$, and step size $=0.100 \mathrm{eV}$ ). An Avio 500 inductively coupled plasma optical emission spectrometer (Perkin Elmer, Waltham, MA, USA) was used to examine the amount of Ce ions present in the electrolyte after the amperometry test for $5 \mathrm{~min}$.

\section{Conclusions}

In this work, we first showed a big data set for the recovery of rare earth ( $\mathrm{La}, \mathrm{Ce}, \mathrm{Pr}, \mathrm{Nd}, \mathrm{Sm}, \mathrm{Eu}$, $\mathrm{Gd}, \mathrm{Tb}, \mathrm{Dy}, \mathrm{Ho}, \mathrm{Er}, \mathrm{Tm}$, and $\mathrm{Yb}$ ) ions over a $\mathrm{Ni}$ sheet in a $0.1 \mathrm{M} \mathrm{NaClO}_{4}$ electrolyte. Cyclic voltammetry tests showed the reduction potentials between -1.2 and $-0.8 \mathrm{~V}$ (vs. $\mathrm{Ag} / \mathrm{AgCl}$ ). The observed reduction potentials were reported for all the RE elements with increasing the atomic number. SEM images showed that the electrodeposition method was useful to recover the RE elements as thin film or nanoparticle structures on a Ni sheet. As the atomic number was increased the morphology was changed from uniform thin film state to nanoparticle structures. The electrodeposited La (\#59) on Ni showed a uniform film morphology while the electrodeposited $\mathrm{Yb}$ (\#70) on a Ni sheet showed nanoparticle morphology. EDXS data confirmed the elements of RE, C, O, and Cl. The EDXS $\mathrm{Ni} L$ signal was used to estimate the relative amounts of electrodeposited RE materials. On the basis of the FT-IR and XRD data, it was tentatively concluded that the electrodeposited recovered materials were of a $\mathrm{RE}_{2}(\mathrm{OH})_{x}\left(\mathrm{CO}_{3}\right)_{y-z}\left(\mathrm{ClO}_{4}\right)_{z} \cdot \mathrm{nH}_{2} \mathrm{O}$ complex. For a selected electrodeposited Eu on $\mathrm{Ni}$, the oxidation state of $3+$ was confirmed by Eu 3d XPS signals. The Eu(III) oxidation state was further confirmed by the PL spectra showing the ${ }^{5} \mathrm{D}_{0} \rightarrow{ }^{7} \mathrm{~F}_{0,1,2,3,4}$ emission transitions in the visible region between 570 and $720 \mathrm{~nm}$. Future potential experiments may include a clear elucidation of the crystal structure, and electrodeposition over a porous Ni mesh for energy storage and energy production (e.g., $\mathrm{CO}_{2}$ reduction and water splitting) electrochemical electrodes.

Overall, the present study contains very valuable electrochemical behaviors of all the RE(III) ions in $\mathrm{NaClO}_{4}$ electrolyte when a Ni sheet is used as a working electrode. The newly established big data set for RE elements could be used to predict the redox behaviors of Ln and An elements present in solutions. Furthermore, their morphologies, chemical states and the electrochemical recovery method could provide valuable information on the reprocessing of used nuclear oxide fuels, the recovery of RE-containing industry wastes, and fabrication of thin films. 
Author Contributions: Conceptualization, C.K.R. and Y.S.; methodology, Y.S.; formal analysis, M.H.J., S.J.P. and S.M.H.; investigation, M.H.J., S.J.P. and S.M.H.; data curation, Y.S.; writing-original draft preparation, M.H.J. and Y.S.; writing-review and editing, C.K.R. and Y.S.; supervision, C.K.R. and Y.S.; funding acquisition, Y.S. All authors have read and agreed to the published version of the manuscript.

Funding: This work was supported financially by the National Research Foundation of Korea (NRF) grant funded by the Korea government (MEST) (2018M2B2A9065523). The APC was funded by NRF-2018M2B2A9065523.

Conflicts of Interest: The authors declare no conflict of interest.

\section{References}

1. Cardoso, C.E.D.; Almeida, J.; Lopes, C.B.; Trindade, T.; Vale, C.; Pereira, M.E. Recovery of Rare Earth Elements by Carbon-Based Nanomaterials-A Review. Nanomaterials 2019, 9, 814. [CrossRef] [PubMed]

2. Wójcik, G. Sorption Behaviors of Light Lanthanides(III) (La(III), Ce(III), Pr(III), Nd(III) and Cr(III) Using Nitrolite. Materials 2020, 13, 2256. [CrossRef] [PubMed]

3. Dev, S.; Sachan, A.; Dehghani, F.; Ghosh, T.; Briggs, B.R.; Aggarwal, S. Mechanisms of biological recovery of rare-earth elements from industrial and electronic wastes: A review. Chem. Eng. J. 2020, 397, 124596. [CrossRef]

4. Wang, Y.; Guo, X.; Bai, Y.; Sun, X. Effective removal of calcium and magnesium sulfates from wastewater in the rare earth industry. RSC Adv. 2019, 9, 33922-33930. [CrossRef]

5. Edahbi, M.; Plante, B.; Benzaazoua, M. Environmental challenges and identification of the knowledge gaps associated with REE mine wastes management. J. Clean. Prod. 2019, 212, 1232-1241. [CrossRef]

6. Binnemans, K.; Jones, P.T.; Blanpain, B.; Van Gerven, T.; Yang, Y.; Walton, A.; Buchert, M. Recycling of rare earths: A critical review. J. Clean. Prod. 2013, 51, 1-22. [CrossRef]

7. Jha, M.K.; Kumari, A.; Panda, R.; Kumar, J.R.; Yoo, K.; Lee, J.Y. Review on hydrometallurgical recovery of rare earth metals. Hydrometallurgy 2016, 165, 2-26. [CrossRef]

8. Binnemans, K.; Jones, P. Perspectives for the recovery of rare earths from end-of-life fluorescent lamps. J. Rare Earths 2014, 32, 195-200. [CrossRef]

9. Yurramendi, L.; Gijsemans, L.; Forte, F.; Aldana, J.L.; Del Río, C.; Binnemans, K. Enhancing rare-earth recovery from lamp phosphor waste. Hydrometallurgy 2019, 187, 38-44. [CrossRef]

10. Liu, H.; Zhang, S.-G.; Pan, D.; Tian, J.; Yang, M.; Wu, M.; Volinsky, A.A. Rare earth elements recycling from waste phosphor by dual hydrochloric acid dissolution. J. Hazard. Mater. 2014, 272, 96-101. [CrossRef]

11. Choi, E.-Y.; Jeong, S.M. Electrochemical processing of spent nuclear fuels: An overview of oxide reduction in pyroprocessing technology. Prog. Nat. Sci. 2015, 25, 572-582. [CrossRef]

12. Abbasalizadeh, A.; Malfliet, A.; Seetharaman, S.; Sietsma, J.; Yang, Y. Electrochemical Recovery of Rare Earth Elements from Magnets: Conversion of Rare Earth Based Metals into Rare Earth Fluorides in Molten Salts. Mater. Trans. 2017, 58, 400-405. [CrossRef]

13. Tunsu, C.; Petranikova, M.; Ekberg, C.; Retegan, T. A hydrometallurgical process for the recovery of rare earth elements from fluorescent lamp waste fractions. Sep. Purif. Technol. 2016, 161, 172-186. [CrossRef]

14. Yang, D.-W.; Liu, Y.-L.; Yin, T.-Q.; Jiang, S.-L.; Zhong, Y.-K.; Wang, L.; Li, M.; Chai, Z.-F.; Shi, W. Application of Binary Ga-Al Alloy Cathode in U Separation from Ce: The Possibility in Pyroprocessing of Spent Nuclear Fuel. Electrochim. Acta 2020, 353, 136449. [CrossRef]

15. Yuan, L.; Yin, T.-Q.; Liu, Y.; Yang, D.; Yan, P.Y.; Wang, G.; Chai, Z. Thermodynamics and Kinetics Properties of Lanthanides (La, Ce, Pr, Nd) on the Liquid Bismuth Electrode in LiCl-KCl Molten Salt. J. Electrochem. Soc. 2020, 167, 122507. [CrossRef]

16. Yang, D.-W.; Chang, K.-K.; Hu, X.-F.; Liu, Y.-L.; Yin, T.-Q.; Jiang, S.-L.; Liu, J.; Han, W.; Chai, Z.-F.; Yuan, L. Electrochemical Behaviors of Eu (III) on the Liquid Binary Al-Ga Alloy Cathode. J. Electrochem. Soc. 2019, 166, D882-D889. [CrossRef]

17. Liu, Y.-L.; Liu, K.; Luo, L.; Yuan, L.; Chai, Z.; Shi, W. Direct separation of uranium from lanthanides (La, Nd, $\mathrm{Ce}, \mathrm{Sm}$ ) in oxide mixture in LiCl-KCl eutectic melt. Electrochim. Acta 2018, 275, 100-109. [CrossRef]

18. Kim, S.; Lee, S.-H. Electrochemical properties of $\mathrm{NdCl}_{3}$ and $\mathrm{CeCl}_{3}$ in molten $\mathrm{LiCl}-\mathrm{KCl}$ eutectic salt. Appl. Sci. 2020, 10, 7252. [CrossRef]

19. Ge, J.; Yang, Q.; Wang, Y.; Zhuo, W.; Du, M.; Zhang, J. Selective Electrodeposition of Europium and Samarium in Molten LiCl-KCl with Copper and Aluminum Electrodes. J. Electrochem. Soc. 2020, 167, 022501. [CrossRef] 
20. Xu, X.; Sturm, S.; Zavašnik, J.; Rozman, K.Z. Electrodeposition of a Rare-Earth Iron Alloy from an Ionic-Liquid Electrolyte. ChemElectroChem 2019, 6, 2860-2869. [CrossRef]

21. Hunter, J.P.; Dolezalova, S.; Ngwenya, B.T.; Morrison, C.A.; Love, J.B. Understanding the recovery of rare-earth elements by ammonium salts. Metals 2018, 8, 465. [CrossRef]

22. Krishna, G.M.; Rout, A.; Venkatesan, K. Voltammetric investigation of some lanthanides in neutral ligand-ionic liquid. J. Electroanal. Chem. 2020, 856, 113671. [CrossRef]

23. Zhang, M.; Zhang, M.; Yan, Y.; Qiu, M.; Chen, J. Theoretical investigation of lanthanide and transition metal on $\mathrm{Al}$ cathode: Equilibrium potential and atomic radii analysis by a mathematical equation. Colloids Surf. A Physicochem. Eng. Asp. 2020, 590, 124490. [CrossRef]

24. NIST DTSA-II Software. Available online: https://cstl.nist.gov/div837/837.02/epq/dtsa2/ (accessed on 30 September 2020).

25. Wu, X.; Li, J.; Zhu, Q.; Liu, W.; Sun, X.; Sakka, Y. One-step freezing temperature crystallization of layered rare-earth hydroxide $\left(\mathrm{Ln}_{2}(\mathrm{OH})_{5} \mathrm{NO}_{3} \cdot \mathrm{nH}_{2} \mathrm{O}\right)$ nanosheets for a wide spectrum of $\mathrm{Ln}(\mathrm{Ln}=\mathrm{Pr}-\mathrm{Er}$, and $\mathrm{Y})$, anion exchange with fluorine and sulfate, and microscopic coordination probed via photoluminescence. J. Mater. Chem. C 2015, 3, 3428-3437. [CrossRef]

26. Kang, J.-G.; Min, B.-K.; Sohn, Y. Synthesis and characterization of $\mathrm{Gd}(\mathrm{OH})_{3}$ and $\mathrm{Gd}_{2} \mathrm{O}_{3}$ nanorods. Ceram. Int. 2015, 41, 1243-1248. [CrossRef]

27. Sohn, $\mathrm{Y} . \mathrm{Yb}_{2} \mathrm{O}_{3}$ nanowires, nanorods and nano-square plates. Ceram. Int. 2018, 44, 3341-3347. [CrossRef]

28. Kang, J.-G.; Gwag, J.S.; Sohn, Y. Synthesis and characterization of $\mathrm{Dy}(\mathrm{OH})_{3}$ and $\mathrm{Dy}_{2} \mathrm{O}_{3}$ nanorods and nanosheets. Ceram. Int. 2015, 41, 3999-4006. [CrossRef]

29. Chen, Y.; Zhang, Y.; Zhao, L.-J. ATR-FTIR spectroscopic studies on aqueous $\mathrm{LiClO}_{4}, \mathrm{NaClO}_{4}$, and $\mathrm{Mg}\left(\mathrm{ClO}_{4}\right)_{2}$ solutions. Phys. Chem. Chem. Phys. 2004, 6, 537. [CrossRef]

30. Li, J.; Li, P.; Li, J.; Tian, Z.Q.; Yu, F. Highly-Dispersed Ni-NiO Nanoparticles Anchored on an $\mathrm{SiO}_{2} \mathrm{Support}^{-}$ for an Enhanced CO Methanation Performance. Catalists 2019, 9, 506. [CrossRef]

31. Zhang, Y.; Cao, H.; Zhang, J.; Xia, B. Synthesis of $\mathrm{LiNi}_{0.6} \mathrm{Co}_{0.2} \mathrm{Mn}_{0.2} \mathrm{O}_{2}$ cathode material by a carbonate co-precipitation method and its electrochemical characterization. Solid State Ion. 2006, 177, 3303-3307. [CrossRef]

32. Antoniou, S.; Pashalidis, I.; Gessner, A.; Kumke, M.U. Spectroscopic investigations on the effect of humic acid on the formation and solubility of secondary solid phases of $\mathrm{Ln}_{2}\left(\mathrm{CO}_{3}\right)_{3}$. J. Rare Earths 2011, 29, 516-521. [CrossRef]

33. NIST. X-Ray Photoelectron Spectroscopy Database; Version 4.1; National Institute of Standards and Technology: Gaithersburg, MD, USA, 2012. Available online: http://srdata.nist.gov/xps/ (accessed on 30 September 2020).

34. Miyakawa, M.; Nakata, M.; Tsuji, H.; Fujisaki, Y. Simple and reliable direct patterning method for carbon-free solution-processed metal oxide TFTs. Sci. Rep. 2018, 8, 12825. [CrossRef] [PubMed]

35. Sahadeo, E.; Song, J.H.; Gaskell, K.; Kim, N.; Rubloff, G.W.; Lee, S.B.; Gaskel, K. Investigation of the water-stimulated $\mathrm{Mg}^{2+}$ insertion mechanism in an electrodeposited $\mathrm{MnO}_{2}$ cathode using X-ray photoelectron spectroscopy. Phys. Chem. Chem. Phys. 2018, 20, 2517-2526. [CrossRef] [PubMed]

36. Lee, S.; Kang, J.-S.; Leung, K.T.; Kim, S.K.; Sohn, Y. Magnetic Ni-Co alloys induced by water gas shift reaction, Ni-Co oxides by CO oxidation and their supercapacitor applications. Appl. Surf. Sci. 2016, 386, 393-404. [CrossRef]

37. Kang, J.-G.; Jung, Y.; Min, B.-K.; Sohn, Y. Full characterization of $\mathrm{Eu}(\mathrm{OH})_{3}$ and $\mathrm{Eu}_{2} \mathrm{O}_{3}$ nanorods. Appl. Surf. Sci. 2014, 314, 158-165. [CrossRef]

38. Hong, S.; Rhee, C.K.; Sohn, Y. Photoluminescence, electro- and thermal catalytic properties of bare and $\mathrm{Eu}(\mathrm{III})$-doped $\mathrm{GaOOH}, \alpha$ - and $\beta-\mathrm{Ga}_{2} \mathrm{O}_{3}$ nanorods. J. Alloy. Compd. 2019, 774, 11-17. [CrossRef]

39. Pawlik, N.; Szpikowska-Sroka, B.; Pisarski, W.A. Energy transfer study on $\mathrm{Tb}^{3+} / \mathrm{Eu}^{3+}$ co-activated sol-gel glass-ceramic materials containing $\mathrm{MF}_{3}(\mathrm{M}=\mathrm{Y}, \mathrm{La})$ nanocrystals for NUV optoelectronic devices. Materials 2020, 13, 2522. [CrossRef]

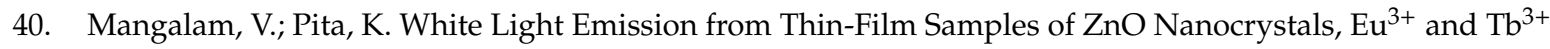
Ions Embedded in an $\mathrm{SiO}_{2}$ Matrix. Materials 2019, 12, 1997. [CrossRef]

Publisher's Note: MDPI stays neutral with regard to jurisdictional claims in published maps and institutional affiliations. 